\title{
Interactions between barotropic tides and mesoscale processes in deep ocean and shelf regions
}

\author{
Emil Vassilev Stanev ${ }^{1}$ (D) $\cdot$ Marcel Ricker ${ }^{2}$
}

Received: 26 April 2019 / Accepted: 21 January 2020 / Published online: 14 March 2020

(C) The Author(s) 2020

\begin{abstract}
The interactions between barotropic tides and mesoscale processes were studied using the results of a numerical model in which tidal forcing was turned on and off. The research area covered part of the East Atlantic Ocean, a steep continental slope, and the European Northwest Shelf. Tides affected the baroclinic fields at much smaller spatial scales than the barotropic tidal scales. Changes in the horizontal patterns of the $\mathrm{M}_{2}$ and $\mathrm{M}_{4}$ tidal constituents provided information about the two-way interactions between barotropic tides and mesoscale processes. The interaction between the atmosphere and ocean measured by the work done by wind was also affected by the barotropic tidal forcing. Tidal forcing intensified the transient processes and resulted in a substantial transformation of the wave number spectra in the transition areas from the deep ocean to the shelf. Tides flattened the sea-surface height spectra down to $\sim \mathrm{k}^{-2.5}$ power law, thus reflecting the large contribution of the processes in the high-frequency range compared to quasi-geostrophic motion. The spectra along sections parallel or normal to the continental slope differ from each other, which indicates that mesoscale turbulence was not isotropic. An analysis of the vorticity spectra showed that the flattening was mostly due to internal tides. Compared with the deep ocean, no substantial scale selectivity was observed on the shelf area. Particle tracking showed that the lengths of the Lagrangian trajectories increased by approximately $40 \%$ if the barotropic tidal forcing was activated, which contributed to changed mixing properties. The ratio between the horizontal and vertical scales of motion varied regionally depending on whether barotropic tidal forcing was included. The overall conclusion is that the barotropic tides affect substantially the diapycnal mixing.
\end{abstract}

Keywords Tides $\cdot$ Mesoscale processes $\cdot$ Nonlinear interactions $\cdot$ Diapycnal mixing $\cdot$ Spectral energy $\cdot$ European Northwest Shelf

\section{Introduction}

Tides are well known to influence turbulent mixing in shallow seas; however, the coupled dynamics of barotropic tides and mesoscale processes along the shelf break and beyond are not well known, particularly for individual ocean areas. Because many ocean circulation models do not simultaneously

This article is part of the Topical Collection on Coastal Ocean Forecasting Science supported by the GODAE OceanView Coastal Oceans and Shelf Seas Task Team (COSS-TT) - Part II

Responsible Editor: Pierre De Mey-Frémaux

Emil Vassilev Stanev

emil.stanev@hzg.de

1 Institute of Coastal Research, Helmholtz-Zentrum Geesthacht, Geesthacht, Germany

2 Institute for Chemistry and Biology of the Marine Environment, University of Oldenburg, Oldenburg, Germany simulate mesoscale eddies and tides, the uncertainties resulting from the underrepresentation of their interactions must be quantitatively assessed. This issue has received wide practical interest because of the forthcoming wide-swath altimetry planned for the Surface Water and Ocean Topography mission (SWOT; Fu et al. 2009; Durand et al. 2010; Qiu et al. 2017). Altimetric observations of shorter mesoscale structures down to $\sim 15 \mathrm{~km}$ constitute a challenge for ocean analysis and forecasting (Bonaduce et al. 2018) and can provide a valuable contribution to operational oceanography (Bell et al. 2015; Le Traon et al. 2017).

The most notable interactions between tidal currents and geostrophic eddies occur when their horizontal scales are comparable (Lelong and Kunze 2013). Furthermore, internal tides occupy the same scales as mesoscale eddies (e.g., Rocha et al. 2016) as well as the scales of geostrophic or submesoscale flows. The transition length and time scales separating geostrophic flows and internal waves depend on the energy level of the mesoscale eddy field (Qiu et al. 2017). This energy level shows a strong regional dependence, which 
gives us the motivation to address the regional flattening of spectral energy due to tides.

Topographic features are important in transferring energy from barotropic to baroclinic tides (Morozov 1995; Ray and Mitchum 1997; Egbert and Ray 2001; Vlasenko et al. 2005; Garrett and Kunze 2007; Wang et al. 2013). Most studies in this field have focused on the generation of and interactions between barotropic and baroclinic tides. Tide-eddy interactions (Richman et al. 2012; Savage et al. 2017; Tchilibou et al. 2018) have not been sufficiently addressed in the transition areas among shelves, continental slopes, and deep oceans. In these transition areas, eddies transport shelf water filaments offshore (Cenedese et al. 2013; Cherian and Brink 2018). The potential vorticity is affected by the shelf break, meaning that the break acts as a barrier to eddies. The impact of topography on tides is also significant and can influence the exchange between oceans and shelf basins.

The theoretical concepts of interactions between barotropic tides and mesoscale eddies, which have been addressed in the above-cited works for different ocean areas, are analyzed here for an ocean area that includes the deep ocean (part of the East Atlantic Ocean), a steep continental slope, and a shallow shelf (most of the North Sea, see Fig. 1). Numerical experiments are performed by turning barotropic tidal forcing on and off in the model, and the model data are analyzed with the aim of quantifying the effects of coupling between tides and currents.

The European Northwest Shelf (ENWS) selected for this study is one of the most-studied ocean areas as far as the tides are concerned. The importance of shelf-deep water interactions has been documented in many experimental and modeling studies (Huthnance 1995; Huthnance et al. 2009; and more recently, Buckingham et al. 2016). However, analyses of realistic model simulations with tides and eddies are limited, both globally and for this region. Tchilibou et al. (2018) performed a similar analysis to what is presented here; however, their study was restricted to the equatorial ocean. Graham et al. (2018a) and Tonani et al. (2019) developed a very fineresolution model $(1.5 \mathrm{~km})$ for the ENWS area. This model was considered as the next-generation ocean forecast model for the ENWS and is used in operational forecasting. The authors performed extensive comparisons with the operational model currently used at the time of their study. However, they did not specifically address the coupled dynamics of barotropic tides and mesoscale processes,

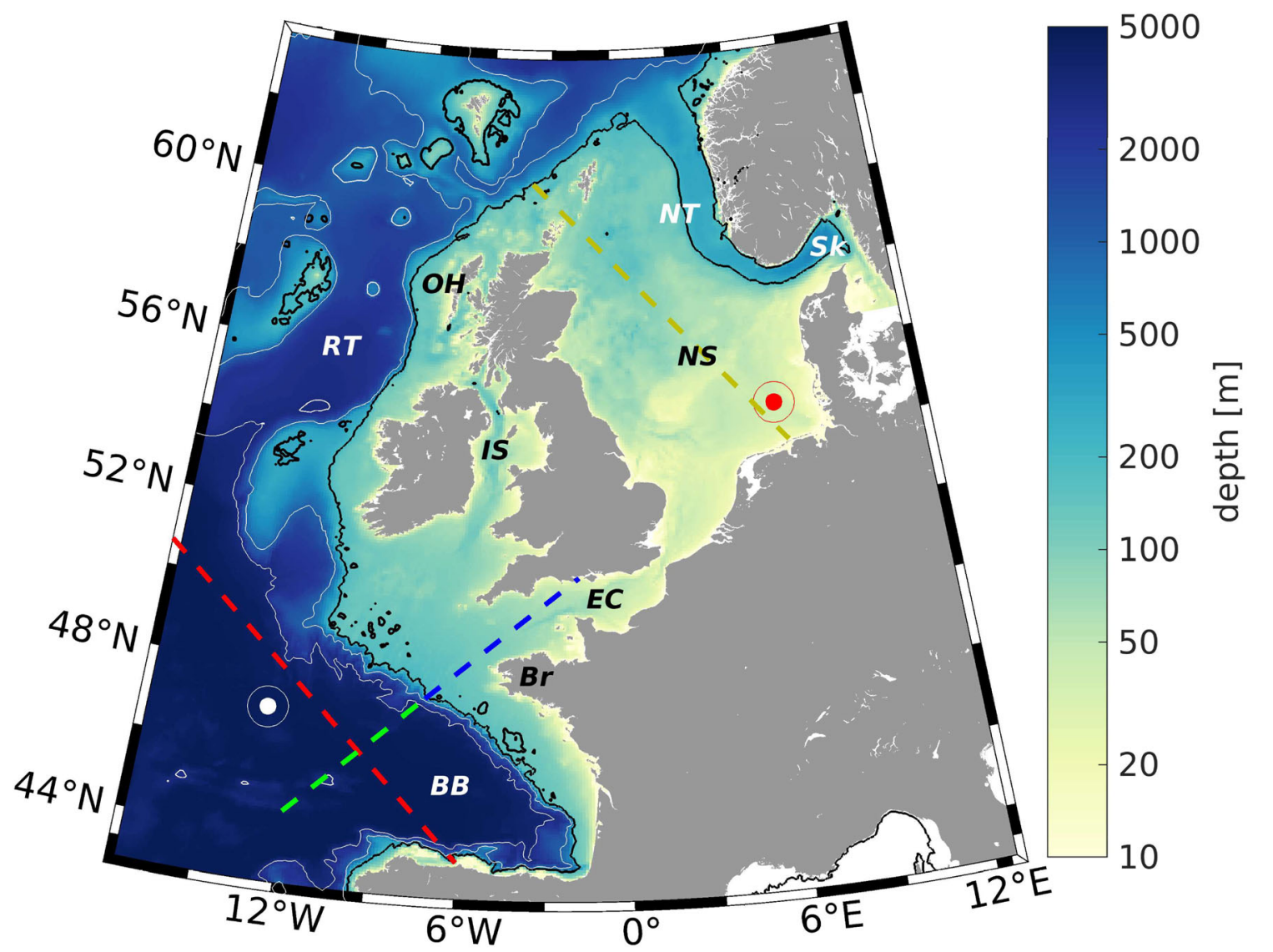

Fig. 1 Bathymetry of the European Northwest Shelf and part of the East Atlantic. Section lines (dashed) and two specific locations (white and red circles) indicate areas where analyses of simulations are discussed in the text. The 200-, 1000-, and 3000-m isobaths are also shown (200-m isobath is plotted in black). The geographic names used in the text are $B B$ - Bay of Biscay, $N S$-North Sea, $I S$-Irish Sea, $R T$-Rockall Trough, Sk-Skagerrak, NT-Norwegian Trench, EC-English Channel, $\mathrm{OH}$ - Outer Hebrides and $\mathrm{Br}$ - Bretagne 
which is the main issue addressed here. Guihou et al. (2017) analyzed the results of numerical simulations with $1.8-\mathrm{km}$ horizontal resolutions in the same region and mainly focused on internal tides and the seasonal and interannual variability of shelf break processes. They demonstrated that internal tides in the region were characterized by complex pycnocline displacement patterns. Recently, another fine-resolution model was developed by Vervatis et al. (2019) for the Bay of Biscay at $1 / 36^{\circ}$ resolution, and it was used to analyze the interaction between open ocean and coastal shelf dynamics. They found that the differences between the along-track altimeter data and simulations in the open ocean were due to mesoscale eddy decorrelation (Vervatis et al. 2019), and this result is also relevant to the major issue addressed here.

Although the horizontal resolution in the present study is coarser than in some of the above-cited studies in the ENWS area, it makes it possible to address some issues of mesoscale dynamics, which have not been fully considered before. To the best of our knowledge, the Lagrangian approach to studying coupling between barotropic tide and mesoscale motions has not been widely explored, although its potential for analyzing and interpreting the dynamics of counter-rotating mesoscale and sub-mesoscale eddies was recently demonstrated by Mantovanelli et al. (2017). By examining the particle trajectories and their differences in models with and without tides, a type of "integrated" representation of transport over certain spatial domains and periods can be obtained, thereby revealing the role of tides.

Another new issue (at least for the area of the present study) is how the mesoscale eddies and their energy cascade vary in response to regional conditions. The comparison of the wave number spectra and their differences in the three zones of interest defined above helps answer this question. The fundamental differences between baroclinic and barotropic dynamics will be illustrated using spectral analyses.

The present study can be considered as a regional one; however, the analyzed processes have much in common with processes that have been observed and simulated elsewhere. The near-coastal effects of barotropic and baroclinic tides on mixing (Suanda et al. 2017) will not be analyzed because they need a finer resolution and the coupling of tides with other processes, e.g., wind waves, which are not included here, play an important role in the near-coastal zone (Schloen et al. 2017).

The paper is structured as follows: Section 2 describes the numerical model; Section 3 presents the basic dynamics; Section 4 addresses the impact of tides on the effects of wind; Section 5 describes the frequency spectra and eddy kinetic energy; Section 6 describes the flattening of wave number spectra due to tides; and Section 7 illustrates an application of the Lagrangian tracking when studying the mechanisms through which barotropic tides interact with mesoscale motion. The paper ends with a short conclusion.

\section{Numerical model}

\subsection{Model area}

The European Slope Current follows the shelf edge (see the isobath $200 \mathrm{~m}$ in Fig. 1), and south of the shelf area lies the Bay of Biscay (BB), which has a complex system of currents, counter-currents (Ferrer et al. 2009), eddies (Pingree and Le Cann 1992) and internal tides (Pichon et al. 2013). Some of the slope current waters enter the English Channel (EC) or the Irish Sea (IS), and other parts follow the western coast of Ireland and continue toward the Outer Hebrides $(\mathrm{OH})$, where another branch enters the North Sea (NS). Some sub-basinscale eddies can be considered trapped by topography, e.g., the eddy in the Rockall Trough (RT). Low-salinity waters from the Baltic Sea entering the North Sea flow through the Skagerrak (Sk) and the Norwegian Trench (NT) as a complex system of currents and counter-currents further diluted by the large runoff along the Scandinavian coast. The tides in the region of our study (Fig. 1) are bathymetrically controlled. The tidal range in the open ocean is $\sim 1 \mathrm{~m}$ and increases to $\sim 5 \mathrm{~m}$ in the Irish Sea and English Channel. The tidal velocities exceed $1 \mathrm{~m} \mathrm{~s}^{-1}$ over large shelf areas and shallow banks.

\subsection{Model setup}

\subsubsection{Model and sub-grid parameterizations}

We use the hydrodynamic ocean model NEMO (Nucleus for European Modelling of the Ocean; https://www.nemo-ocean. $\mathrm{eu} /$; Madec 2008); its setup is similar to that of the operational model for the ENWS (O'Dea et al. 2012) known as the Atlantic Margin Model (AMM7, https://marine.copernicus. eu). Notably, "7" reflects the horizontal resolution in kilometers. In the vertical direction, $51 \sigma$-layers are specified. Sub-grid parameterizations for tracers use a Laplacian operator (the coefficient of horizontal eddy diffusivity is $50 \mathrm{~m}^{2} \mathrm{~s}^{-1}$ ). Momentum diffusion is parameterized using a biharmonic operator (the respective coefficient is $1 \times 10^{10} \mathrm{~m}^{4} \mathrm{~s}^{-1}$ ). Turbulence closure is based on the GLS $k-\varepsilon$ scheme, and the background vertical eddy viscosity is taken as $10^{-6} \mathrm{~m}^{2} \mathrm{~s}^{-1}$. Nonlinear bottom friction with a minimum drag coefficient of $10^{-3}$ is used. Observations are not assimilated here.

\subsubsection{What the model can and cannot resolve}

With the described resolution and parameterizations, the model resolves tidal mixing on the shelf and the formation of tidal fronts (for different aspects of resolution problems, see also Polton 2015 and Holt et al. 2017). As demonstrated by Graham et al. (2018a), the simulated positions of tidal fronts are close in models with $\sim 7$ and $\sim 1.5-\mathrm{km}$ resolution. Guihou 
et al. (2017) analyzed the differences between two configurations of NEMO (one with 1.8-km resolution and another configuration in which the horizontal resolution was identical with the one used here) and claimed that the seasonal cycle was well reproduced in all configurations. The modification of tidal ellipse by stratification (Souza and Simpson 1996) is also resolved with the resolution here.

At least two grid points per radius of deformation are needed to resolve an eddy (Hallberg 2013); therefore, for the resolution used, eddies with diameters larger than $30-40 \mathrm{~km}$ can be resolved as well as long internal tides (internal tides have the same length scales as eddies). Luneva et al. (2015) demonstrated that with a resolution even coarser than the one used here but applied to the Arctic, where the Rossby radius is smaller than that in our model area, the model reasonably simulates (1) the role of strong shear stresses generated by the tidal currents, (2) the impact of tides on the thickness of boundary layers, and (3) the intensification of vertical motions over rough bottom topography.

What the model does not fully resolve are eddies on the shelf and shelf break. According to Guihou et al. (2017), $\mathrm{M}_{2}$ baroclinic wavelength at the shelf break is $\sim 25 \mathrm{~km}$. Therefore, the presentation of the internal tides on the shelf and shelf break could be biased by a resolution of $7 \mathrm{~km}$. As demonstrated by Graham et al. (2018b), NEMO configurations with 7and $1.5-\mathrm{km}$ resolutions give similar representations of the mean downwelling circulation; however, the latter is $\sim 20 \%$ stronger if the resolution is $1.5 \mathrm{~km}$.

\subsubsection{Model forcing and initialization}

Three-hourly air-sea flux and hourly $10-\mathrm{m}$ wind and air pressure data from the UK Met Office atmospheric model were used for atmospheric forcing. River runoff was based on climatological data. The open boundary forcing had two parts: a tidal harmonic signal (15 constituents, Q1, O1, P1, S1, K1, 2N2, MU2, N2, NU2, M2, L2, T2, S2, K2, M4) and the remaining barotropic part consisting of the sea surface elevation and depth-mean currents (2D surge component). Barotropic forcing was implemented following the Flather radiation scheme (Flather 1994). In addition to tidal harmonic forcing, tidal potential forcing using the same tidal constituents was applied over the entire model area. The effects of self-attraction and loading are not included (for their importance in the area of our numerical simulations, see Irazoqui Apecechea et al. (2017)).

The initial data were taken from the AMM7 operational model (https://marine.copernicus.eu).

\subsection{Model integration and analysis}

The period of integration analyzed here was from 1 January 2014 to 31 December 2015 after 1 year of spin up. In this experiment, which was named the control run experiment (CRE), barotropic tidal forcing was enabled. Another experiment in which barotropic tidal forcing was turned off on 1 January 2014 was implemented for the same period (1 January 2014 to 31 December 2015). This experiment was initialized using the simulations from the CRE and called the non-tidal experiment (NTE). A third experiment similar to the CRE was performed, in which only the $\mathrm{M}_{2}$ constituent was retained in the tidal forcing, and it was called the $\mathrm{M}_{2}$ experiment $\left(\mathrm{M}_{2} \mathrm{E}\right)$.

The kinetic energy at $100 \mathrm{~m}$ after the modes have reached steady state, averaged over the entire area, shows a similar temporal variability in CRE and NTE: lower energy in the summer and higher in the winter (Fig. 2). The highfrequency oscillations are very different in the two models. In CRE, the neap-spring variability is dominant, while the oscillations in the winter months in the NTE are mostly due to wind forcing.

A combination of the Eulerian and Lagrangian approaches was used to analyze the results of the numerical experiments. The choice of the second approach was justified by the fact that the trajectories provide an accurate representation of the
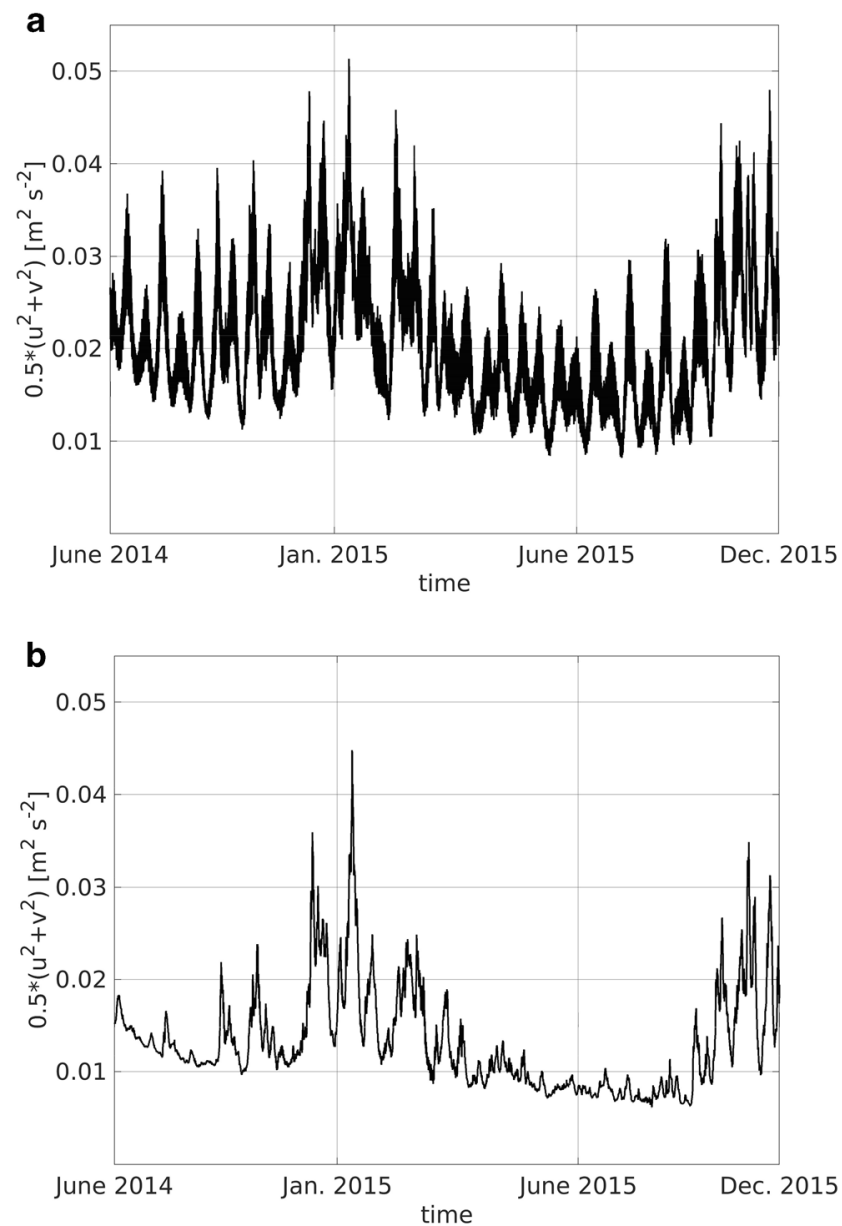

Fig. 2 Kinetic energy at $100 \mathrm{~m}$ averaged for the entire model area in CRE (a) and NTE (b) 
dominant pathways of water flow. By comparing the results from the CRE and NTE, we identify areas and processes that are most sensitive with respect to tidal influences.

FFT analysis and tidal analysis performed with the tidal harmonic analysis method UTide (Codiga 2011) were used to process the model results.

\section{Analysis of simulated dynamics}

\subsection{Validation of simulated tides against FES data}

Tidal dynamics in the East Atlantic Ocean and the ENWS have been addressed in numerous studies; however, very fine-resolution simulations using baroclinic models were first presented in the works of Maraldi et al. (2013), Guihou et al. (2017), and Graham et al. (2018a). In the following, the amplitudes and phases of the dominant tide $\left(\mathrm{M}_{2}\right)$ in the region are compared with the available FES data from the Global Tidal Model (Carrere et al. 2013). The present simulations are consistent with the FES data (Fig. 3a-c). The largest amplitudes occurred around the British Isles, near the shelf in front of the French coast and along the south North Sea coasts. In the areas
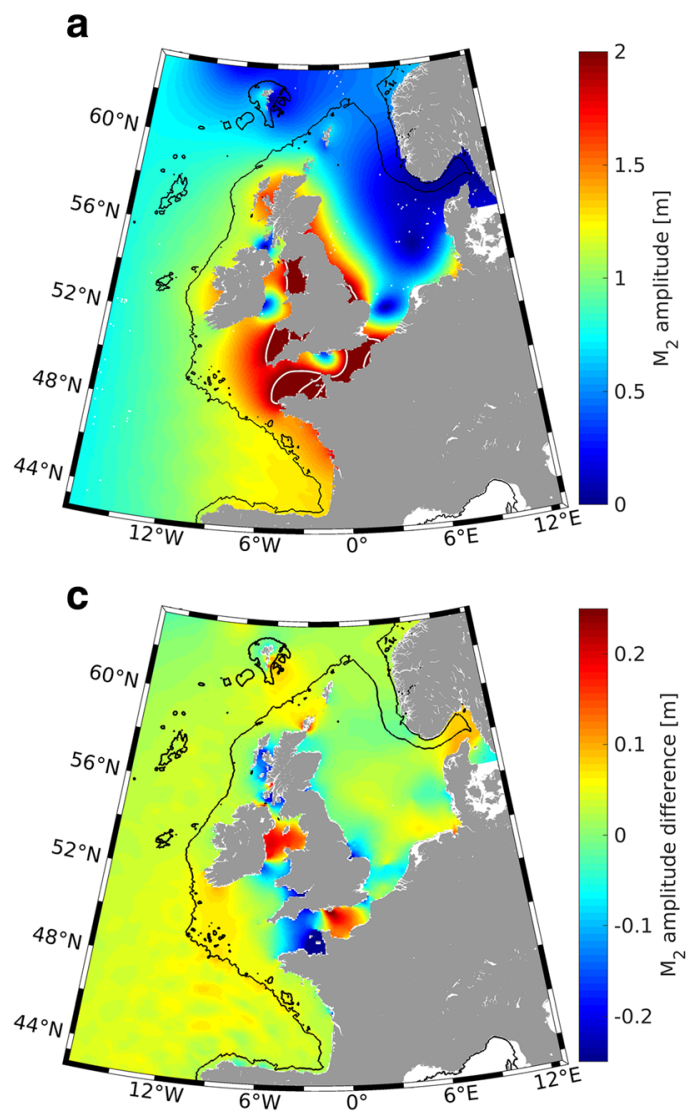

Fig. 3 Amplitude of the $\mathrm{M}_{2}$ tide in CRE for the period of 1 January to 30 June 2015 computed from the simulated sea level using UTide (a). The white isolines are 3, 4, and $5 \mathrm{~m}$. Comparison of the simulations in CRE with the largest differences between the simulations and FES data (Irish Sea and English Channel, Fig. 3c), the relative errors in the amplitude were below $15 \%$. Our simulations compare well with the ones in the above-cited works using finer resolution. Guihou et al. (2017), who compared NEMO configurations of the North West European Shelf and Atlantic Margin with $\sim 1.8-\mathrm{km}$ and $7-\mathrm{km}$ resolutions, demonstrated that tidal processes, particularly those in deep water areas, are also well resolved with a coarser resolution.

\subsection{Transport pathways affected by tides}

Lagrangian particles were released in CRE and NTE on 1 January 2015 in each grid box. The tracking was implemented online; that is, in the model, particles were advected by the 3D velocity field at every model time step. An hourly sampling of the model results ensured that the effect of high-frequency motion was correctly resolved in the analysis. The trajectories of Lagrangian particles in the CRE and NTE tracked for 10 days displayed some similarities and several fundamental differences (Fig. 4a, b). The large-scale patterns of surface circulation were generally similar (e.g., the anti-clockwise circulation in the North Sea). One year after the tidal forcing was

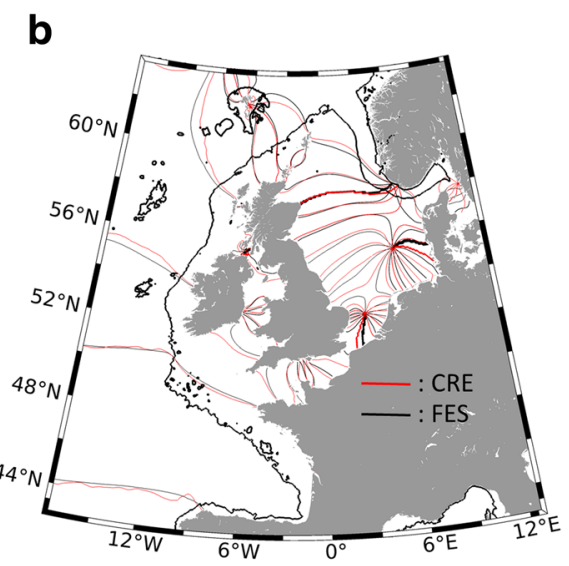

and FES data for the $\mathrm{M}_{2}$ tide phases (b): black lines-FES, and red lines - CRE. The difference between amplitudes in FES and CRE (c) 

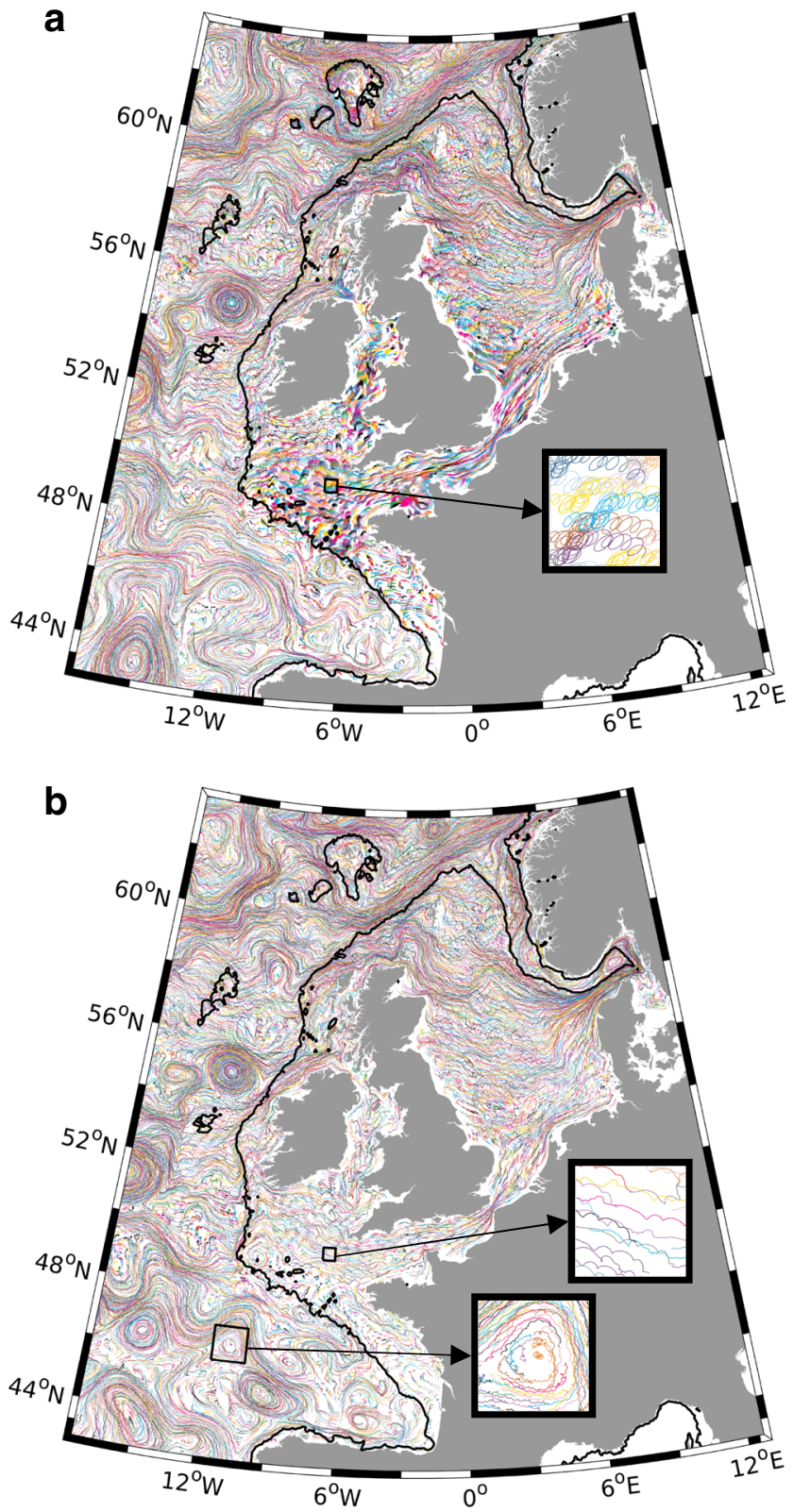

Fig. 4 Trajectories of every 5 th particle released at the surface are tracked over 10 days starting on 1 January 2015 in the CRE (a) and NTE (b) cases. Different colors for each particle were chosen randomly based on the scheme of van Sebille et al. (2018) to distinguish different trajectories. The insets show trajectories in the selected areas in detail

turned off, the eddy field underwent substantial changes; however, the scales of the eddies did not change dramatically. Some quasi-permanent eddies, e.g., the eddy in the Rockall Trough, occurred in the two simulations. The trajectories on the shelf look as plotted with thick lines in the CRE. The latter is a representation problem (see the insets in Fig. 4a, b) because the tidal excursions (greater than $10 \mathrm{~km}$ long) are at least an order of magnitude longer than the displacements associated with the mean circulation. These periodic displacements are represented in the large map as a thickening of the trajectories (compare with the inset in Fig. 4a). In the deep ocean, the mean velocities are large, and the tidal oscillations only slightly undulate the trajectories. When the tidal forcing is turned off (NTE), the trajectories are much smoother (Fig. $4 b)$ and relatively thin. The undulations in the inset in Fig. $4 \mathrm{~b}$ illustrate the inertial motions. One of the main objectives of this study, as defined in the introduction, is to determine whether these tiny tidal displacements substantially affect ocean circulation and identify the respective consequences.

\subsection{Imprints of mesoscale processes on the tidal constituents}

The joint effects of barotropic tides and eddies on the water masses are revealed by the difference between the simulations in the CRE and NTE. The analysis below is provided 1 year after turning the tidal forcing off. The differences in the $\mathrm{M}_{2}$
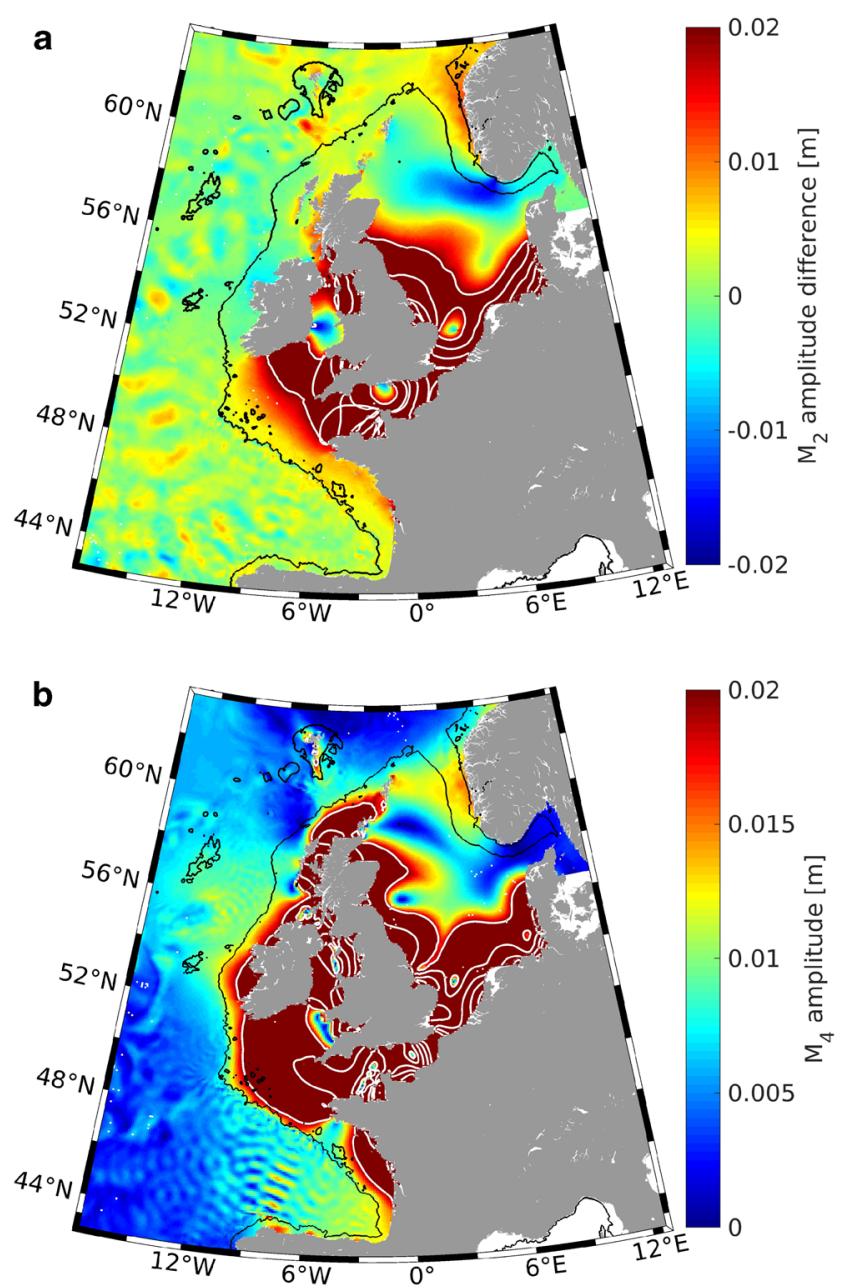

Fig. 5 Difference between the $\mathrm{M}_{2}$ amplitudes from tidal analyses of the simulated sea level using UTide over two 90-day periods: April-June 2015 and January-March 2015 (a). To visualize large and small differences on the same plot, isolines from 2 to $14 \mathrm{~cm}$ in $2 \mathrm{~cm}$ steps are also shown. $\mathrm{M}_{4}$ tidal amplitude estimated using tidal analysis from the differential signal of CRE-NTE for the period 1-31 January 2015 (b). The white isolines are $2,5,10,15$, and $20 \mathrm{~cm}$ 
amplitudes from tidal analyses of CRE estimated for two 3month periods (Fig. 5a) provide information about the incoherent component of tides, which can vary in time due to stratification variations (Zaron 2017) or interactions with eddies (Ponte and Klein 2015). The horizontal scales of the difference field in the deep ocean are comparable to the eddy scales, suggesting that this incoherence is due to the interaction between tides and eddies. The strong amplitudes of internal tides in the deep part of our model area (see also Pichon et al. 2013; Guihou et al. 2017) and their comparable scales with the ones of eddies also suggest that internal tides and mesoscale eddies are the processes that cause the difference patterns in Fig. 5a.

The large-scale (and relatively smooth) patterns in Fig. 5a on the shelf, where the sea level is largely barotropic and circulation is strongly dissipative in comparison to the circulation in the deep ocean, are explained by the large scales of wind field and tides as well as by the large scales of their interaction patterns (Jacob and Stanev 2017). The localized areas on the shelf with the smallest differences between the two periods coincide with the main amphidromic points, where the amplitudes of $\mathrm{M}_{2}$ tides are always low; therefore, the differences are also low.

The nonlinearities due to advection are responsible for the generation of overtides $\left(\mathrm{M}_{4}\right)$. The $\mathrm{M}_{4}$ tidal amplitudes are small compared to those of the $\mathrm{M}_{2}$ tide; however, they contribute to tidal asymmetries that affect the transport of matter. Therefore, the $\mathrm{M}_{4}$ tides are dynamically very important. To visualize the overtides in the deep ocean, where they have very low amplitudes compared to other oscillations, we present in Fig. $5 \mathrm{~b}$ the $\mathrm{M}_{4}$ tidal amplitude of the difference-signal CRE-NTE. Noteworthy is that this pattern is not a snapshot. It is derived from tidal analysis with UTide (Codiga 2011); thus, it provides a stable estimate for a long time. The patterns in Fig. $5 \mathrm{~b}$ are similar to the wave trains in the Bay of Biscay analyzed by Pichon et al. (2013) and Guihou et al. (2017). This result suggests that nonlinear processes (manifested here by the amplitude of the $\mathrm{M}_{4}$ overtide) play a role in the interactions between the baroclinic and barotropic tides. In other words, the generation of overtides cannot be considered in isolation from the generation of internal tides. Furthermore, the imprint of mesoscale motion in the patterns of $\mathrm{M}_{2}$ and $\mathrm{M}_{4}$ tidal amplitudes would not occur without interactions between the small- and large-scale motions.

\section{Impact of tides on the effects of wind}

The dissipation of tidal energy at the bottom is one of the most important mechanisms responsible for the interior mixing of the ocean (Munk and Wunsch 1998). However, the issue of the impact of tides on the work done by wind at the ocean surface, which is a measure of the mechanical forcing of the ocean, has been less researched. Shakespeare and Hogg (2019) demonstrated that the wave momentum flux associated with non-negligible bottom flows over seafloor topography enhances near-surface eddy flows due to the preferential dissipation that occurs when waves propagate in the same direction as the local flow. Similar and even simpler mechanism associated with tidally driven motion could affect the direct forcing by wind.

The work done by wind can be calculated as a scalar product between wind stress and surface current. During the tidal cycle, surface currents change a lot with respect to the dominant wind direction. Therefore, the work done by wind should change depending on the tide. To simplify the below analysis, we assume a linear approximation of wind stress, according to which the scalar product between wind and surface current can be considered as a measure of the work done by wind. Issues about the appropriate parameterization of the air-sea momentum exchange are not considered here.

The scalar product of $10-\mathrm{m}$ wind and surface current in the CRE during January 2015 is shown in Fig. 6a. This product can be considered as a proxy of the work done by wind. The largest anomalies are associated with the mesoscale eddies and the Norwegian current where surface current changes direction over relatively small distances. In large areas over the North Sea, this product is relatively uniform.

The difference between scalar products in the CRE and NTE (Fig. 6b) shows that the change of the work done by wind caused by tides is locally comparable to the work itself. The largest changes are observed in the regions of mesoscale eddies. The difference pattern in the North Sea is also patchy; however, the differences between the two experiments are smaller than that in the deep ocean. The patchy structure of the difference pattern in the area of baroclinic eddies gives another illustration of the impact of the barotropic tides on the mesoscale dynamics. The basic conclusion from Fig. $6 \mathrm{~b}$ in the context of the major research question addressed in the present study is that the interaction between the atmosphere and ocean at monthly scales is not independent on the barotropic tides. Of particular interest is that in the area with nearly barotropic circulation (the shallow Nord Sea), the impact of tides on the direct mechanical forcing from the atmosphere is smaller than in the deep ocean (baroclinic and eddy dominated).

As the averaging period is increased to 1 year, the work done by wind decreases because the atmospheric driving in summer months is weaker (Fig. 2). The basic difference between the monthly and annual mean situations (Fig. 6a, c) is observed in the deep ocean. More interesting is the annual difference pattern (CRE-NTE), which demonstrates that tides tend to reduce the effects of wind in the area of strong tidal currents (English Channel and Southern German Bight). In the deep ocean, the pattern is still patchy but more diffuse compared to the January pattern. A deeper analysis that includes more accurate parameterizations of at-sea momentum 

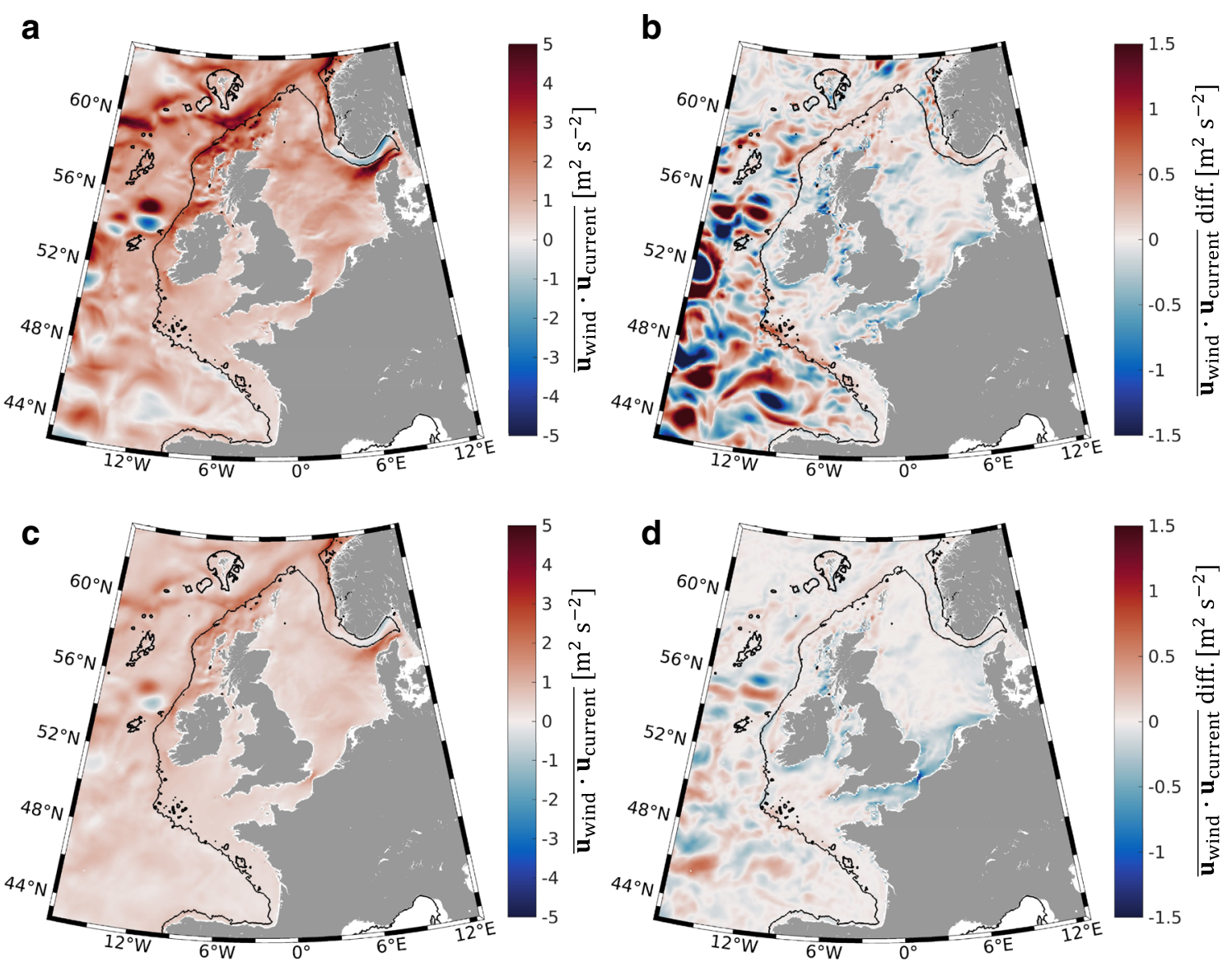

Fig. 6 Panels on the top: average scalar product of 10-m wind and surface velocity in CRE during January 2015 (a) and the difference between (a) and the same plot in the NTE during January 2015 (b). Panels on the

bottom (c, d) show the same as on the top; however, the averaging is for the entirety of 2015

exchanges and over larger areas is necessary to be carried out in the future.

\section{Frequency spectra and eddy kinetic energy}

The inertial period in the model area ranges between 18.75 and $13.30 \mathrm{~h}$. The velocity spectrum in the deep ocean location marked by the white symbol in Fig. 1 reveals clear inertia and $\mathrm{M}_{2}$ maxima, the latter of which disappears in the NTE (Fig. 7a). The amplitudes of inertial oscillations in the NTE are slightly larger than those in the CRE, which indicates that tides do not enhance these oscillations.

Oscillations with inertial frequency do not appear in the shallow station in the German Bight (red dot in Fig. 1). This finding supports the drifter observations of Meyerjürgens and Ricker (personal communication), thus demonstrating that the dissipative processes in the shallow areas, where the depth is comparable to the Ekman depth, are too strong and suppress the development of inertial waves. Furthermore, the amplitudes of the $\mathrm{M}_{2}$ tide estimated from $\mathrm{u}$-velocities are 3-4 times higher in the shallow location than in the deep ocean (compare Fig. 7a and b). This comparison is meaningful because the $\mathrm{M}_{2}$ amplitude of u-velocity does not change much in the upper $100 \mathrm{~m}$ in the deep ocean location (the magnitudes are 9.1 and $8.9 \mathrm{~cm} \mathrm{~s}^{-1}$ at sea surface and at $100 \mathrm{~m}$, respectively).

Here, we define the eddy kinetic energy (EKE) as

$\mathrm{EKE}=\frac{\overline{u^{2}}+\overline{v^{2}}}{2}-\frac{\bar{u}^{2}+\bar{v}^{2}}{2}=\frac{\left(\overline{u^{2}}-\bar{u}^{2}\right)+\left(\overline{v^{2}}-\bar{v}^{2}\right)}{2}$,

where the overbar represents time averaging (entirety of 2015). Thus, EKE accounts for all types of transient processes, including internal tides (not only quasi-geostrophic (QG) turbulence). The eddy kinetic energy (EKE) in the CRE and NTE shows large differences (Fig. 8a, b), particularly on the shelf of the Biscay Bay and in the shallow area around the Faroe Islands. The topography is relatively shallow in these areas, and tides impose important control on regional dynamics. Moreover, the NTE displays low energy conditions. The relative change in the EKE between the two experiments (Fig. 8c) can be used to identify the regions affected by tides. These areas are mainly at shallow depths as also noted in the regional 

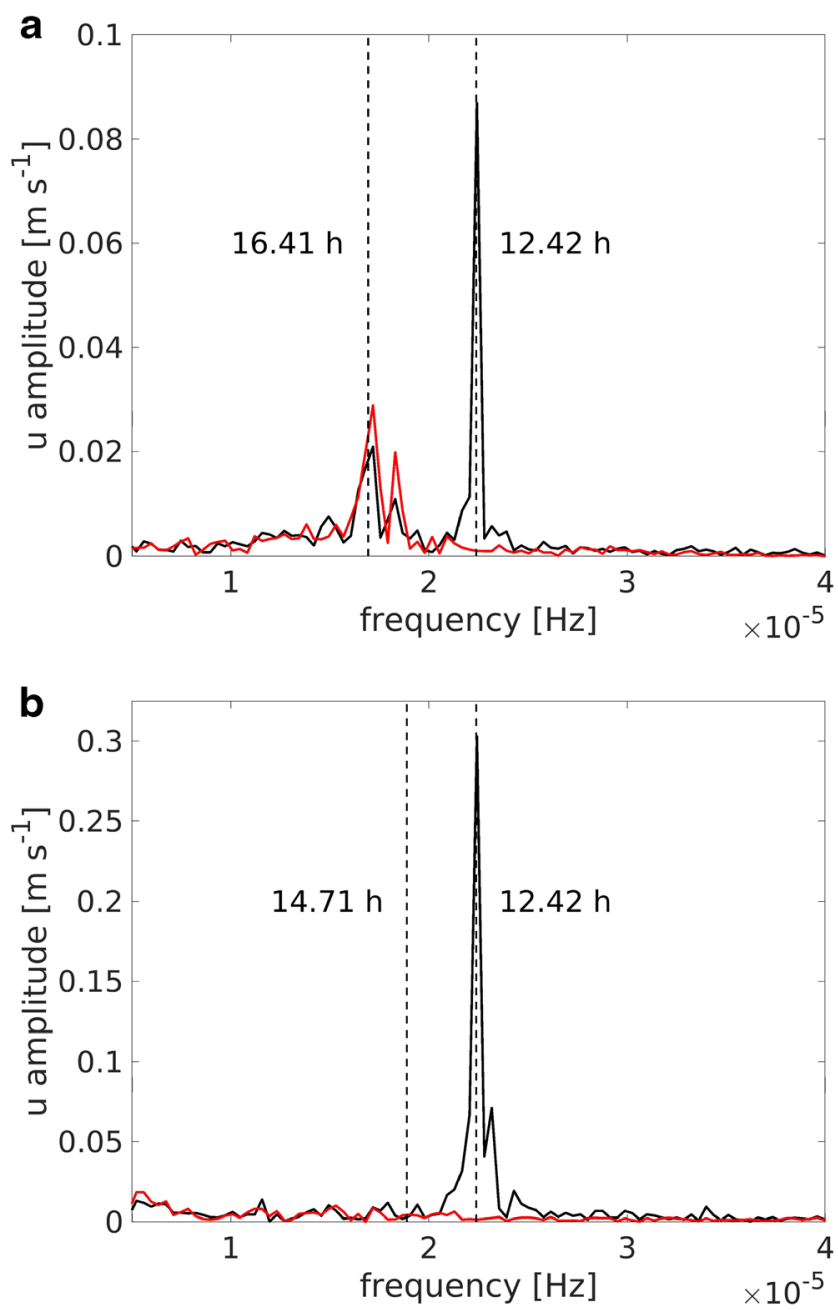

Fig. 7 Frequency spectrum of the u velocity at $100 \mathrm{~m}$ in the deep ocean (a) and at the sea surface in the German Bight (b) (for the position of stations, see Fig. 1) for the period of 1-31 January 2015 (a). Black line$\mathrm{CRE}$, and red line-NTE. The dashed vertical lines indicate the inertial and $\mathrm{M}_{2}$ frequencies

study of Huthnance et al. (2009), who found that mixing over slopes affects the structure of the density field in the ocean. The patchiness of the patterns in Fig. 8c beyond the continental slope reveals coherent structures on the scales of ocean eddies. Figure 8 would suggest that barotropic tides amplify the mesoscale motion. This issue will be addressed in more detail in Section 6, where we analyze the wave number spectra.

The above results could be subject to inappropriate separation of signals with different periods. For instance, rather strong tidal constituents, such as the spring-neap tidal cycle, which has a period of $\sim 14$ days, are present along with other harmonics as diurnal tides and their modulations. The comparison between $\mathrm{M}_{2} \mathrm{E}$ with the other two experiments demonstrates that the relative difference between the responses to real and monochromatic forcing are very small on the shelf (Fig. 8d). However, in these areas, the largest differences between the CRE and NTE are observed (Fig. 8c). The conclusion is that the $\mathrm{M}_{2}$ tide is the dominant one in these areas. The patchy pattern in the deep ocean demonstrates that the combined effect of all tidal frequencies except $\mathrm{M}_{2}$ is not negligible, particularly in the Bay of Biscay, which is an area of strong mesoscale eddies and internal tides.

\section{Wave number spectra: flattening due to tides}

The spectral slopes of sea surface height (SSH) computed from altimeter data (Le Traon et al. 2008; Xu and Fu 2012) are flatter than those corresponding to the $\mathrm{k}^{-5}$ law known from the theory of QG turbulence (Hua and Haidvogel 1986). According to this theory, the $\mathrm{k}^{-5}$ law for SSH is equivalent to the $\mathrm{k}^{-3}$ law for EKE, and the energy and enstrophy cascades in the inertial subrange determine the shape of the spectra. A number of works using numerical modeling and observations (Richman et al. 2012; Dufau et al. 2016; Ray and Zaron 2016) have addressed various reasons for spectral flattening, such as the regional and process dependence of spectral laws.

The diverse conditions in the studied region allow us to study the transformation of spectra in the deep and shallow oceans as well as the role of tides in this process. Spectral slopes are analyzed along the three transects in Fig. 1: in the shallow North Sea; in the Bay of Biscay almost parallel to the continental slope, and in the Bay of Biscay almost perpendicular to the continental slope and extending in the direction of the English Channel (Fig. 9a). The inset in Fig. 9a shows the topographies along these sections. The lengths of the first two segments are 991 and $1391 \mathrm{~km}$, which are similar to the data segment lengths reported by $\mathrm{Xu}$ and $\mathrm{Fu}$ (2012). The results for the third transect will be addressed separately for the deep ocean and shelf to avoid the mixing of data associated with processes influenced by different dynamics (see also Qiu et al. (2017), who argue that similar divisions help to ensure the spatial homogeneity of the regional eddy variability). The respective segment lengths of $\sim 500 \mathrm{~km}$ are similar to those used by Dufau et al. (2016). The two vertical dashed lines in Fig. 9 between 70 and $250 \mathrm{~km}$ define the global mesoscale band (Xu and $\mathrm{Fu} 2012$ ), which is well resolved by the model.

Tides in the CRE tend to increase the spectral power for the entire interval from $800 \mathrm{~km}$ to the smallest scales resolved, which is illustrated by the fact that the full lines in Fig. 9a are above the respective dashed lines of the same color. The spectral slopes are very different for the different sections and different wave numbers. In the deep ocean (red lines), a low slope $\left(\sim \mathrm{k}^{-1}\right)$ area extends to a scale of approximately $300 \mathrm{~km}$. Then, an interval with a steep spectral slope approaching $\sim \mathrm{k}^{-5}$ follows in the NTE (dashed red and green lines show almost the same spectral slope in the interval between 200 and $100 \mathrm{~km}$ ). This interval can be considered as an analogue of mesoscale turbulence in the inertial subrange. At very small scales $(<70 \mathrm{~km})$, the spectral slope decreases again. When 

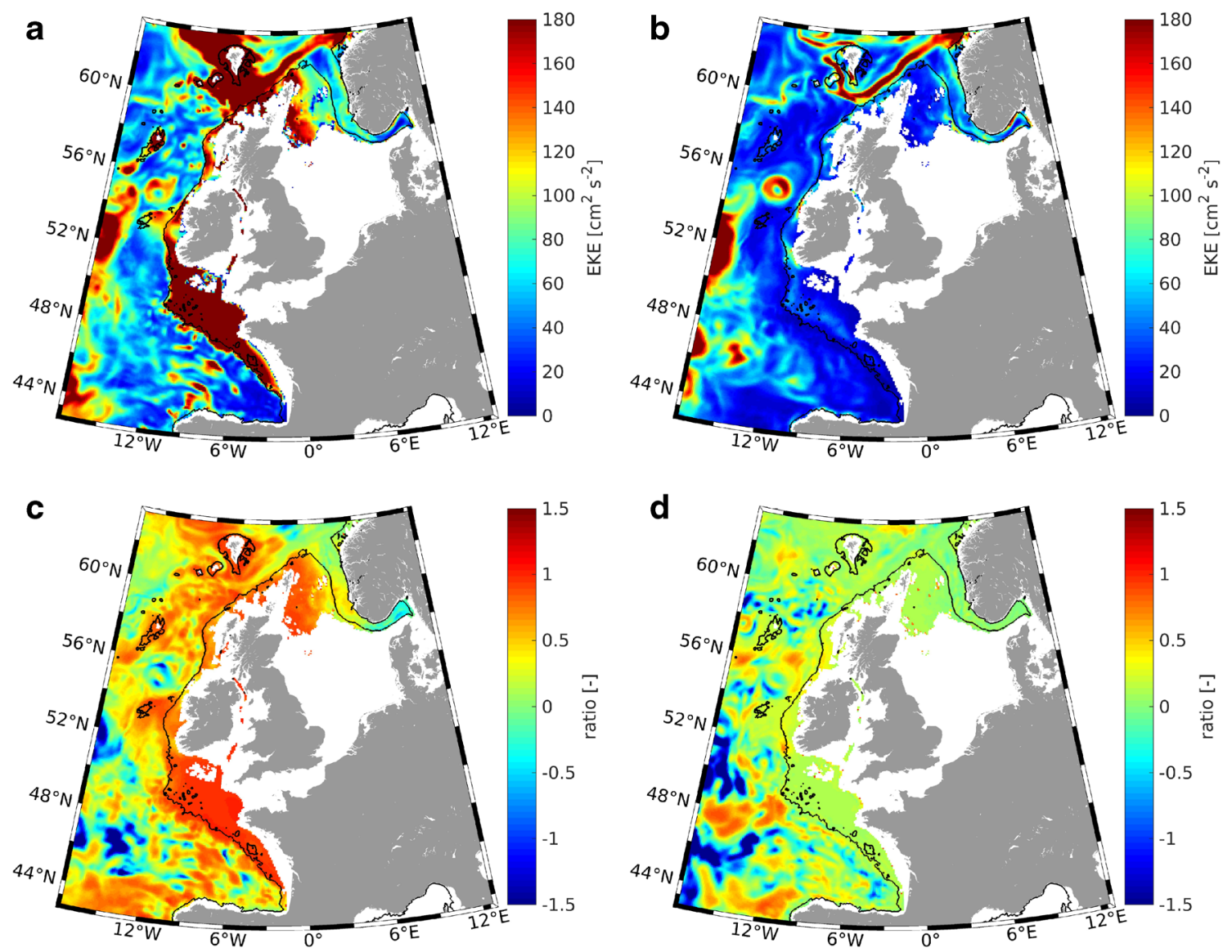

Fig. 8 EKE at $100 \mathrm{~m}$ in 2015 from CRE (a) and NTE (b). The difference between $\mathbf{a}$ and $\mathbf{b}$ normalized by $\mathbf{a}$ is shown in $\mathbf{c}$. Panel $\mathbf{d}$ is similar to $\mathbf{c}$, the difference is that the EKE at $100 \mathrm{~m}$ simulated in $\mathrm{M}_{2} \mathrm{E}$ is subtracted from the EKE at $100 \mathrm{~m}$ simulated in CRE

barotropic tides are included in the model forcing (CRE), the spectrum in the mesoscale interval flattens (full red line in Fig. 9a). Specifically, the spectral slope is $\sim \mathrm{k}^{-2.5}$, which is in the range of spectral slopes $\mathrm{k}^{-2}-\mathrm{k}^{-4}$ in extratropical zones (Le Traon et al. 1990; Xu and Fu 2012; Dufau et al. 2016). The flattening is indicative of the increase in the relative strength of processes in the high-frequency range compared to those related to QG motion (Richman et al. 2012).

The section perpendicular to the continental shelf is too short to resolve the large-scale motion. This section displays lower energy than that observed along the section parallel to the continental slope (green lines are below the respective red lines). In the mesoscale range, both the dashed green and dashed red curves tend to follow the power law $\sim \mathrm{k}^{-5}$. However, the former gets closer to the $\sim \mathrm{k}^{-5}$ law at smaller scales than the dashed red line but follows this power law over wider wave number ranges compared with the dashed red curve.

QG turbulence theory predicts a power law $\sim \mathrm{k}^{-5}$ under the assumptions of statistical homogeneity and isotropy. The anisotropic behavior revealed by the difference between the spectral slopes along the sections parallel and normal to the continental slope suggests a substantial difference in the cascading of energy in the two directions, which indicates that the shelf break acts as a barrier to eddies. Similar anisotropy was observed by Rocha et al. (2016) in the Drake Passage and explained as due to the contribution of ageostrophic flows.

The distance between the red and green curves in the NTE (dashed) is much larger than that in the CRE (full red and green curves). This difference increases as the scale of motion decreases. However, the red and green full lines (CRE) are almost parallel in the mesoscale range. This finding indicates that the flattening of spectra caused by tides (CRE) is relatively stronger for the motion across the continental slope.

Sea surface spectra are subject to rotational and potential motions. Knowing that internal tides and mesoscale eddies share the same horizontal scales, it is difficult to conclude from Fig. 9a whether the flattening of the spectra is caused by internal tides or by mesoscale rotational motions. To answer this question (to separate eddies and tides), an additional analysis is presented below on the vorticity spectra in the deep ocean where internal tides are important (Fig. 9b). The motivation for this analysis stems from the fact that tides are mostly potential flows, and a strong difference between spectra in the CRE and NTE would represent a convincing result of the effects of tides on eddies. In the area between the two vertical 

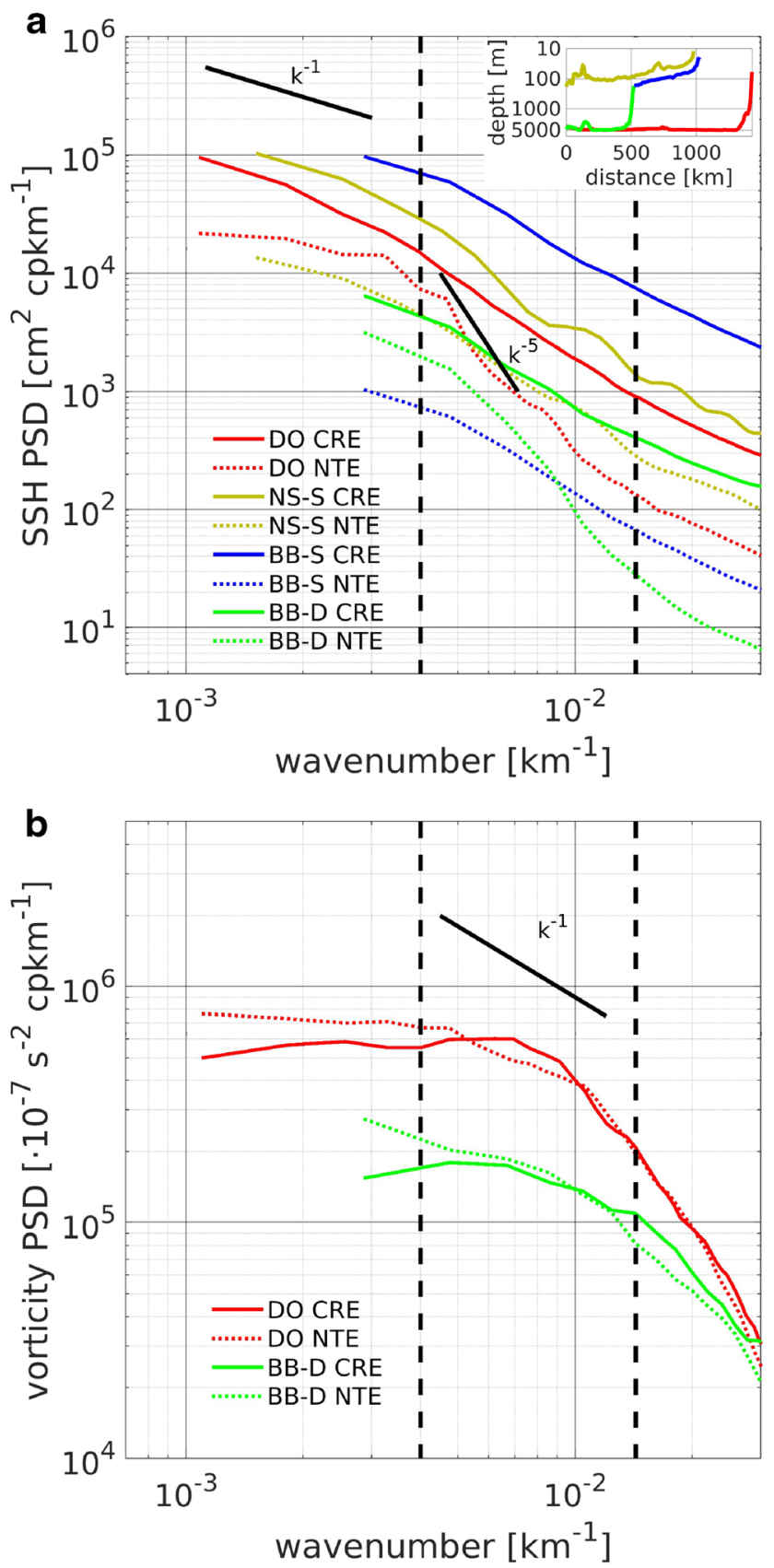

Fig. 9 SSH spectrum along the transect lines in Fig. 1 averaged from January to June 2015 (a). The topography along these section lines plotted in Fig. 1 (from the west to east) is shown in the inset. Vorticity spectrum along the deep ocean transects is shown in $\mathbf{b}$. The legend explains the data used and the correspondence (colors) with the section lines in Fig. 1. The abbreviations used are DO (deep ocean), NS-S (North SeaShelf), BB-S (Bay of Biscay-Shelf), and BB-D (Bay of Biscay-deep ocean). Vertical dashed line marks the mesoscale range from 70 to $250 \mathrm{~km}$

dashed lines (scales between 70 and $250 \mathrm{~km}$ ), the spectral slopes along the two sections in the deep ocean is $\sim \mathrm{k}^{-1}$ (the $\mathrm{k}^{-1}$ vorticity spectral slope corresponds to the $\mathrm{k}^{-5}$ power law for sea surface height, that is, QG turbulence). Within the high wave number part of this range and down to the smallest resolved scales, the dashed and full red lines in Fig. 9b are closer to each other than they are for the SSH spectrum (compare with Fig. 9a). This result suggests that the flattening of spectra of sea surface height in the CRE along the section parallel to the coast was primarily due to the internal tide.

In the direction normal to the continental slope the difference between vorticity spectra with and without tides is stronger than along the section parallel to the coast (compare the differences between the two red and two green curves). The difference between the two green curves provides evidence of the effects of barotropic tides on the mesoscale dynamics in the cross-shore direction. For both sections shown in Fig. 9b, the differences in motion between the CRE and NTE appear more substantial for larger scales, for which spectral slopes are very flat, particularly in the CRE. Similar conclusions follow for the analysis of the spectra of sea surface height if the data are first de-tided. Obviously, the role of tides is also important for the rotational motion at large mesoscales.

Some further differences between the along-slope and across-slope vorticity spectra are also noteworthy. For scales below $60 \mathrm{~km}$, full and dashed red lines (along-slope direction) practically coincide. In the across-slope direction, full and dashed green lines deviate from each other for small-scale motion, which would suggest that variability associated with the rotational motion is also important for spectral flattening at these scales.

The spectral regime on the shelf is relatively simpler. The respective lines in the CRE and NTE (yellow and blue in Fig. 9) are almost parallel and flat $\left(\sim \mathrm{k}^{-2}\right)$, which indicates that no scale-dependent decay of the spectral slope occurred. Along both transect lines, tides resulted in an increase in energy; however, this increase was much stronger on the shelf of Bretagne (the difference between the two blue lines is much greater than that between the two red ones). Thus, the shelf of Bretagne is an area of major EKE enhancement caused by tides (see also Fig. 8). The difference between the deep ocean and shelf spectra (scale-dependent versus non-scaledependent spectral slopes) further highlights the difference between the barotropic and baroclinic dynamics. For the former, the SSH is affected by mass changes, and for the latter, steric effects caused by eddies and internal tides are dominant. Analyses of different parts of these transects and other similar transects (not shown) demonstrated that the above estimates are robust.

\section{Lagrangian view of dynamics caused by tides}

In Section 3, we described the transport patterns affected by tides to illustrate the difference between the solutions in CRE and NTE. Namely, we visualized the trajectories of Lagrangian particles in the two experiments by focusing on 
tiny tidal excursions that become obvious after magnifying the presentation in specific regions. The Lagrangian approach seems to be useful when illustrating how tides affect the motion because it provides an integrated over time view of the dynamics. In other words, integrating tidal excursions caused by barotropic forcing, which have scales of several to tenths of kilometers, over a certain period could provide useful information about the tidal motion in baroclinic oceans. In the following, the difference between the simulations in the CRE and NTE will be interpreted as a measure of the role of barotropic tidal forcing, which is the only difference between the two experiments.

Two Lagrangian simulations have been carried out, one with each model, which started on 1 January 2015. Seeding is uniform, with one particle per grid released at $150 \mathrm{~m}$. Particles are considered to be displaced by the $3 \mathrm{D}$ velocity field, and Lagrangian tracking is performed online. The results below are shown for the first week of January 2015, and they are referenced with respect to the start position. For example, the travel distance of an individual particle is mapped in the position where it was released. The travel distances in the horizontal direction are shown in Fig. 10a (CRE) and Fig. 10b (NTE). Both patterns reveal similarities, particularly in the regions of eddies and strong fronts. Other similarities can also be mentioned, such as for the region of the Rockall Trough, where the length of trajectories in the two experiments mostly reflect the strong local eddy. A striking difference between the two experiments is that (1) the travel distance in the horizontal direction is overal shorter in the NTE than the CRE. (2) The magnitude of tidally induced motion, as indicated by the difference in lengths of the Lagrangian trajectories in the two experiments, is comparable with the magnitude of motion in the NTE (compare Fig. 10c and b). (3) Particles released on the shelf break in the NTE undergo a shorter travel distance compared to their counterparts in the CRE (compare Fig. 10a and b). The differences between trajectories on the shelf break was an expected result (the tidal rectification on the shelf is well known, Huthnance 1973;
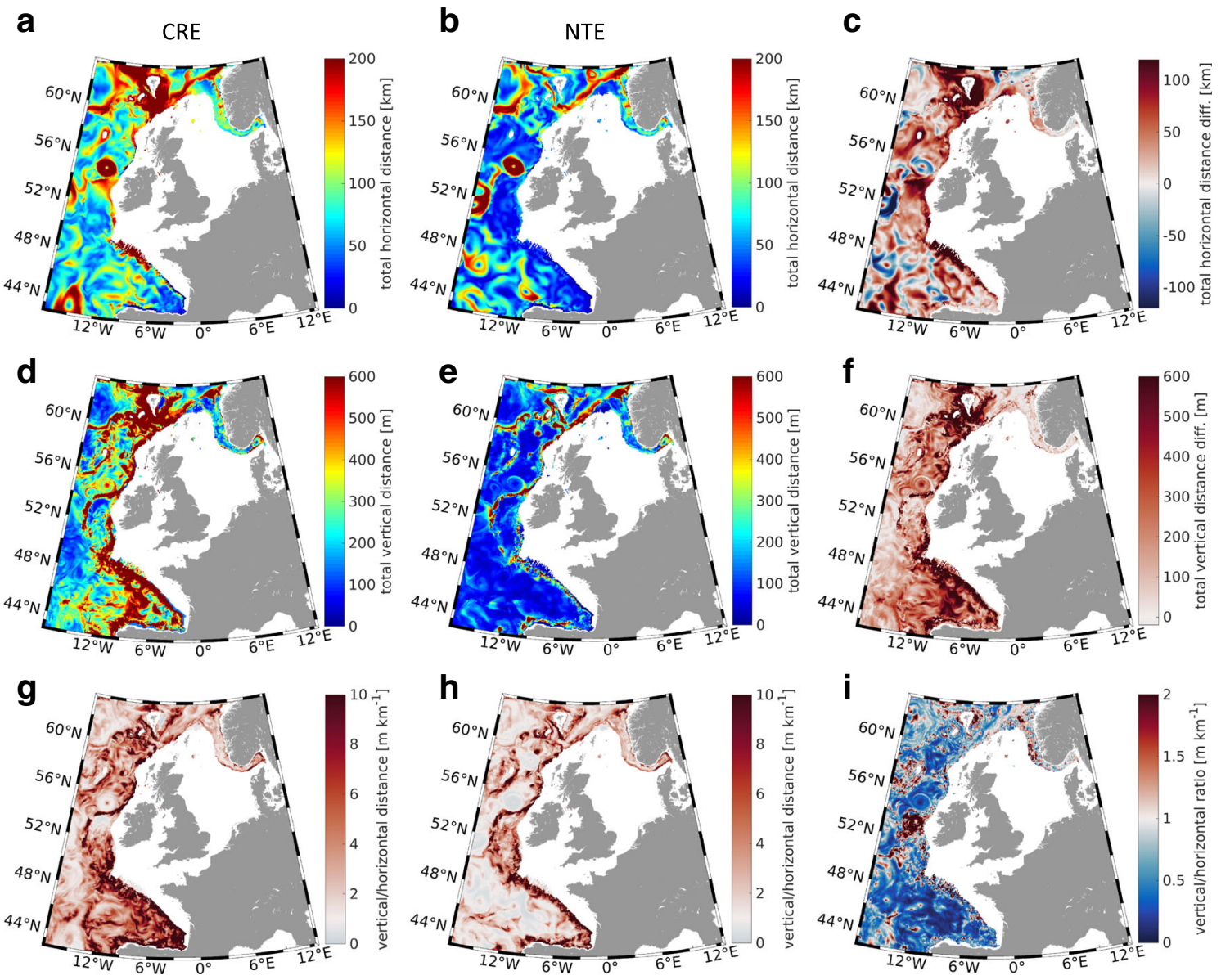

Fig. 10 Results from Lagrangian tracking experiments; particles were released at $150 \mathrm{~m}$. Figures on the top show the traveled distance (length of trajectory) in the horizontal direction during the first week of January 2015 in CRE (a) and NTE (b). c Difference between a and b. Figures in the middle $(\mathbf{d}-\mathbf{f})$ are similar to $\mathbf{a}-\mathbf{c}$; the difference is that the traveled

distance is defined as the sum of individual displacements in the vertical direction; figures on the bottom $(\mathbf{g}, \mathbf{h})$ show the ratio between the respective plots in $\mathbf{d}$, e and $\mathbf{a}, \mathbf{b}$ (e.g. $g=d / a)$ and indicate the ratio between the vertical and horizontal scales of motion; and (i) ratio between $\mathbf{h}$ and $\mathbf{g}$ 
Polton 2015); however, these differences in the areas covered by baroclinic eddies were also considerable. The above results would suggest that the longer trajectories in the CRE would result in more mixing (this is in concert with the flattening of the spectrum discussed in the previous section).

To reveal the differences between the trajectories of Lagrangian particles in the deep ocean and on the shelf break, we sum up the lengths $(L)$ of all trajectories, which start where the bottom is deeper than $1000 \mathrm{~m}$, and separately where the bottom is shallower than $1000 \mathrm{~m}$. We denote these lengths as $L_{\mathrm{D}}{ }^{\mathrm{C}}, L_{\mathrm{D}}{ }^{\mathrm{N}}, L_{\mathrm{S}}{ }_{\mathrm{S}}^{\mathrm{C}}$, and $L_{\mathrm{S}}{ }^{\mathrm{N}}$, where the indices $\mathrm{D}, \mathrm{S}, \mathrm{C}$, and $\mathrm{N}$ correspond to "deep", "slope", "CRE" and "NTE," respectively. The ratios measuring the effect of barotropic tides in the two regions are $L_{\mathrm{D}}{ }^{\mathrm{C}} / L_{\mathrm{D}}{ }^{\mathrm{N}}=1.20$ and $L_{\mathrm{S}}{ }^{\mathrm{C}} / L_{\mathrm{S}}{ }^{\mathrm{N}}=1.99$. Obviously, the increase of the trajectory length in the horizontal is more pronounced for the particles released in the area of continental slope.

The plots in the second row of Fig. 10 are the same as those on the top but the individual displacements are projected on the vertical axis; thus, these figures have to be considered as accumulated vertical displacements over 1 week. A substantial difference is observed between the horizontal and vertical patterns (compare Fig. 10a, b with Fig. 10d, e). The maxima in the vertical displacements follow a very narrow band along the continental slope ( $\sim 1000-\mathrm{m}$ isobath). In both models, an accumulation of vertical displacements is observed around the seamounts in the southwestern part of the model area (compare with the bathymetry in Fig. 1); however, the respective magnitude is much larger in CRE. Furthermore, the distance covered by particles for the period analyzed here is an order of magnitude larger than their displacement from their seeding positions. This finding suggests that mixing associated with the up-and-down motion could be very important. The differential patterns of horizontal (Fig. 10c) and vertical (Fig. 10f) displacements in the two experiments indicate that barotropic tidal forcing has different effects on horizontal and vertical motion.

Again, as in the case of the horizontal movement, we will denote these lengths in the vertical as $Z_{\mathrm{D}}^{\mathrm{C}}, Z_{\mathrm{D}}{ }^{\mathrm{N}}, Z_{\mathrm{S}}^{\mathrm{C}}$, and $Z_{\mathrm{S}}^{\mathrm{N}}$, where the indices have the same meaning as before. The respective ratios in the two experiments are $Z_{\mathrm{D}}{ }^{\mathrm{C}} / Z_{\mathrm{D}}{ }^{\mathrm{N}}=2.23$ and $Z_{\mathrm{S}}^{\mathrm{C}} / Z_{\mathrm{S}}^{\mathrm{N}}=2.37$. In the open ocean, the relative increase of the trajectory length in the vertical caused by the barotropic tidal forcing is almost twice the relative increase of the trajectory length in the horizontal direction $(2.23 / 1.20=1.86)$. The respective ratio for the particles released on the continental slope is substantially lower: $2.37 / 1.99=1.19$.

The ratio between the vertical and horizontal scales of motion is a fundamental characteristic of ocean dynamics. Normally, this ratio is considered to be $\sim 10^{-3}$ or smaller for large-scale ocean motion. The ratio between horizontal and vertical displacements in the CRE (the values in panel d divided by the values in panel a, Fig. 10g) display patterns in the deep ocean that are consistent with the eddy structure of circulation. This ratio ranges between $10^{-2}$ and $10^{-3}$, and the largest values occur in the mesoscale eddies. Approaching the continental slope, the scales of motion decrease and the ratio increases. The similarity between the two models is most pronounced in the area of continental slope. However, over most of the model area, the barotropic forcing resulted in an increase of the vertical excursions of particles in comparison to the excursions in the horizontal direction (compare Fig. $10 \mathrm{~g}$ and $\mathrm{h}$ ).

Figure 10i shows the ratio between Fig. $10 \mathrm{~h}$ and $\mathrm{g}$ and provides an idea of the local $Z_{\mathrm{D}}{ }^{\mathrm{C}} / Z_{\mathrm{D}} \mathrm{N} / L_{\mathrm{D}}{ }^{\mathrm{C}} / L_{\mathrm{D}}{ }^{\mathrm{N}}$ (respectively local $Z_{\mathrm{S}}^{\mathrm{C}} / Z_{\mathrm{S}}^{\mathrm{N}} / L_{\mathrm{S}}{ }^{\mathrm{C}} / L_{\mathrm{S}}{ }^{\mathrm{N}}$ on the continental slope). This ratio compares the slope of velocity vector for the analyzed period against the vertical in the two experiments, which demonstrates some fundamental differences between the horizontal and vertical scales of motion. The ranges are larger than tenfold. The overall trend is that on the shelf break, the motion in the CRE tends to develop relatively smaller vertical displacements relative to the horizontal ones $\left(Z_{\mathrm{S}}{ }^{\mathrm{C}} / Z_{\mathrm{S}}{ }^{\mathrm{N}} / L_{\mathrm{S}}{ }^{\mathrm{C}} / L_{\mathrm{S}}{ }^{\mathrm{N}}=\right.$ 1.19; $Z_{\mathrm{D}}{ }^{\mathrm{C}} / Z_{\mathrm{D}}{ }^{\mathrm{N}} / L_{\mathrm{D}}{ }^{\mathrm{C}} / L_{\mathrm{D}}{ }^{\mathrm{N}}=1.86$ ). In the deep ocean, for the relatively short period of analysis, the patterns are mixed, and in different areas of the eddy field, the velocity vectors become more, or less, sloped against the horizontal plane. However, the overall trend is that in the NTE, the velocity vector in the deep ocean is more aligned to the horizontal plane than in the CRE (Fig. 10i). These regional differences are in concert with the discussed in the previous section spectral flattening, which is also spatially non-isotropic. As demonstrated by Rocha et al. (2016), this anisotropic behavior can be explained as due to the contribution of ageostrophic flows.

An analysis over longer times should reduce the contrasts in the open sea, which, in the current examples, are caused by mesoscale eddies. However, the Lagrangian presentation is
Fig. 11 Temporal change of density at the current position of a Lagrangean particle released at $150 \mathrm{~m}$ in the location denoted in Fig. 1 by a white circle, along with its respective geopotential depth (see legend)

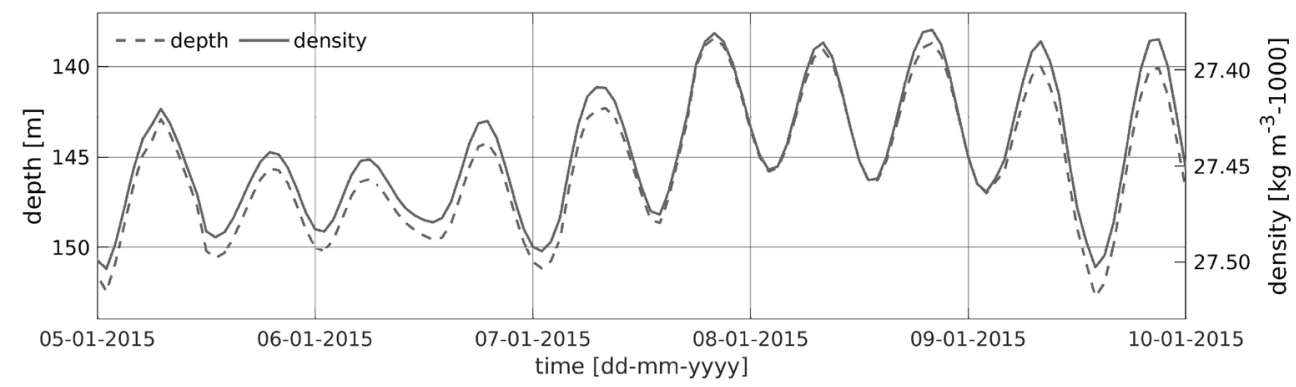


not consistent over long times because the movement of individual particles cannot be adequately mapped in the position of their origin. The Eulerian analysis would be more appropriate in this case.

One final and very principle question remains to be answered: "is the advection of Lagrangian particles entirely (or mostly) isopycnal or not? The answer is given in Fig. 11, where we show the density in the position occupied by a particle, along with its geopotential depth. Obviously, the depth and density are positively correlated, that is the upward displacement is identified not only by the shallower depth, but also by the lower density. Isopycnal mixing would suggest that density remains constant, which is not the case here. The tidal nature of the signal is also very clearly displayed in this figure demonstrating that the barotropic tides tend to increase the diapycnal mixing.

\section{Conclusions}

Adding barotropic tides as open boundary forcing and tidal potential forcing over the entire model area of a NEMO setup for the ENWS and deep ocean around it substantially affected the model dynamics. The overall conclusion from the numerical experiments is that the barotropic tidal forcing (large-scale features as seen in the sea level), which is the only difference between the CRE and NTE, affects the baroclinic fields at small spatial scales. The similarity of the patterns of the $\mathrm{M}_{4}$ tide and wave trains in the Bay of Biscay suggests that the generation of overtides and internal tides are strongly coupled or can be considered related to the process of nonlinear tidal distortion. The respective interactions are not one-way processes. The tidal analysis demonstrated that eddy signals were traceable in the horizontal patterns of the $\mathrm{M}_{2}$ and $\mathrm{M}_{4}$ tidal constituents. The same holds for the work done by wind, which was substantially affected by the barotropic tidal forcing.

The spectral slope of the SSH in the experiment in which barotropic tides were turned off approached $\mathrm{k}^{-5}$ along a section parallel to the continental slope, thus demonstrating that the regional dynamics were dominated by mesoscale turbulence. However, in the perpendicular direction, the spectral slope was relatively flat and far from the state of QG turbulence. These differences (in the absence of tides) reflected the changing relative strength of the processes in the highfrequency range compared to that of QG motion, and respectively the anisotropic energy cascades along and across the slope. This finding suggests that the shelf break acts as a barrier to eddies.

Without tides, the spectral slope was relatively flat along the section normal to the continental slope, while the flattening caused by tides appeared more pronouncedly for motion along the continental slope. Analysis of vorticity spectra showed that this flattening was mostly due to the internal tides. This finding suggested that the differences between CRE and NTE, which is shown by the particle tracking experiments, could be considered as an amplification of the effects caused by internal tides in the areas dominated by mesoscale eddies. The conclusion is that tidal dynamics substantially affected the energy cascades among scales in the areas dominated by mesoscale motions (beyond the continental slope). No scale-selective decay of the spectral slope occurred at the shelf, illustrating the difference between the barotropic and baroclinic dynamics.

The Lagrangian tracking experiments with tides turned on and off demonstrated that the barotropic tidal forcing resulted in a substantial change in the length of particle trajectories. The ratio between the vertical and horizontal scales of motion also changed, revealing a pronounced regional dependence. This suggests that the barotropic tides, causing very tiny $3 \mathrm{D}$ oscillations of water parcels, affect substantially the diapycnal mixing, which explains the flattening of wave number spectra.

These regional results are expected to be valid for similar ocean cases in which the effects of eddies influence both ocean dynamics and ecosystems (Chelton et al. 2011; Gaube et al. 2014; Stanev et al. 2014; McGillicuddy Jr. 2016; Vervatis et al. 2019). Furthermore, adding barotropic tides to the forcing of eddy-resolving models is advisable. These results reflect the response to barotropic tidal forcing for scales resolved by the model. Further analyses are needed using higher resolution models in order to more accurately represent the small-scale processes in the slope area and on the shelf, which would ensure a more comprehensive analysis of tidecirculation interactions.

Acknowledgments The authors thank S. Grayek and J. Staneva for the discussion and help in preparing the model. The UK Metoffice is also acknowledged for their support of our modeling efforts. J. SchulzStellenfleth assisted in implementing the spectral analyses.

Funding information Open Access funding provided by Projekt DEAL. This study received support from the project "Macroplastics Pollution in the Southern North Sea - Sources, Pathways and Abatement Strategies" (grant no. ZN3176), which is funded by the Ministry of Science and Culture of the German Federal State of Lower Saxony. Support from the Initiative and Networking Fund of the Helmholtz Association through the project "Advanced Earth System Modelling Capacity (ESM)" was also received for this study.

Open Access This article is licensed under a Creative Commons Attribution 4.0 International License, which permits use, sharing, adaptation, distribution and reproduction in any medium or format, as long as you give appropriate credit to the original author(s) and the source, provide a link to the Creative Commons licence, and indicate if changes were made. The images or other third party material in this article are included in the article's Creative Commons licence, unless indicated otherwise in a credit line to the material. If material is not included in the article's Creative Commons licence and your intended use is not permitted by statutory regulation or exceeds the permitted use, you will need to obtain permission directly from the copyright holder. To view a copy of this licence, visit http://creativecommons.org/licenses/by/4.0/. 


\section{References}

Bell M, Schiller A, Traon P-YL, Smith N, Dombrowsky E, WilmerBecker K (2015) An introduction to GODAE OceanView. J Oper Oceanogr 8:s2-s11. https://doi.org/10.1080/1755876X.2015. 1022041

Bonaduce A, Benkiran M, Remy E, Le Traon PY, Garric G (2018) Contribution of future wide-swath altimetry missions to ocean analysis and forecasting. Ocean Sci 14:1405-1421

Buckingham CE, Naveira Garabato AC, Thompson AF, Brannigan L, Lazar A, Marshall DP, George Nurser AJ, Damerell G, Heywood KJ, Belcher SE (2016) Seasonality of submesoscale flows in the ocean surface boundary layer. Geophys Res Lett 43:2118-2126. https://doi.org/10.1002/2016GL068009

Carrere L, Lyard F, Cancet M, Guillot A, Roblou L (2013) FES 2012: a new global tidal model taking advantage of nearly 20 years of altimetry. In: 20 Years of Progress in Radar Altimetry, vol 710, Venice, p 13

Cenedese C, Todd RE, Gawarkiewicz GG, Owens WB, Shcherbina AY (2013) Offshore transport of shelf waters through interaction of vortices with a shelfbreak current. J Phys Oceanogr 43(5):905-919. https://doi.org/10.1175/JPO-D-12-0150.1

Chelton DB, Gaube P, Schlax MG, Early JJ, Samelson RM (2011) The influence of nonlinear mesoscale eddies on near-surface oceanic chlorophyll. Science. 334(6054):328-332

Cherian DA, Brink KH (2018) Shelf flows forced by deep ocean anticyclonic eddies at the shelf break. J Phys Oceanogr 48(5):1117-1138

Codiga DL (2011) Unified tidal analysis and prediction using the UTide Matlab functions. In: Technical report 2011-01. Graduate School of Oceanography, University of Rhode Island, Narragansett 59pp

Egbert GD, Ray R (2001) Estimates of M2 tidal energy dissipation from TOPEX/Poseidon altimeter data. J Geophys Res 106(22):475-22 502

Dufau C, Orsztynowicz M, Dibarboure G, Morrow R, Le Traon P-Y (2016) Mesoscale resolution capability of altimetry: present and future. J Geophys Res Oceans 121:4910-4927. https://doi.org/10. 1002/2015JC010904

Durand M, Fu L-L, Lettenmaier DP, Alsdorf DE, Rodriguez E, EstebanFernandez D (2010) The surface water and ocean topography mission: observing terrestrial surface water and oceanic submesoscale eddies. Proc IEEE 98:766-779

Ferrer L, Fontán A, Chust G, Mader J, González M, Valencia V, Uriarte A, Collins MB (2009) Low salinity plumes in the oceanic region of the Basque Country. Cont Shelf Res 29(8):970-984

Flather RA (1994) A storm surge prediction model for the Northern Bay of Bengal with application to the cyclone disaster in April 1991. J Phys Oceanogr 24(1):172-190. https://doi.org/10.1175/15200485(1994)024<0172:ASSPMF>2.0.CO;2

Garrett CJR, Kunze E (2007) Internal tide generation in the deep ocean. Annu Rev Fluid Mech 39:57-87

Gaube P, McGillicuddy DJ, Chelton DB, Behrenfeld MJ, Strutton PG (2014) Regional variations in the influence of mesoscale eddies on near-surface chlorophyll. J Geophys Res C Ocean 119(12):81958220. https://doi.org/10.1002/2014JC010111

Graham JA, O'Dea E, Holt J, Polton J, Hewitt HT, Furner R, Guihou K, Brereton A, Arnold A, Wakelin S, Sanchez JMC, Adame CGM (2018a) AMM15: a new high-resolution NEMO configuration for operational simulation of the European north-west shelf. Geosci Model Dev 11(2):681-696

Graham JA, Rosser JP, O'Dea E, Hewitt HT (2018b) Resolving shelf break exchange around the European northwest shelf. Geophys Res Lett 45. https://doi.org/10.1029/2018GL079399

Guihou K, Polton J, Harle J, Wakelin S, O'Dea E, Holt J (2017) Kilometric scale modeling of the North West European Shelf Seas: exploring the spatial and temporal variability of internal tides. J
Geophys Res Oceans 123:688-707. https://doi.org/10.1002/ 2017JC012960

Fu LL, Alsdorf D, Rodriguez E, Morrow R, Mognard N, Lambin J, Vaze P, and Lafon T (2009)The SWOT (surface water and ocean topography) mission: spaceborne radar interferometry for oceanographic and hydrological applications, in: OCEANOBS'09 conference, 2125 September 2009, Venice, Italy

Hallberg R (2013) Using a resolution function to regulate parameterizations of oceanic mesoscale eddy effects. Ocean Model 72:92-103. https://doi.org/10.1016/j.ocemod.2013.08.007

Holt J, Hyder P, Ashworth M, Harle J, Hewitt HT, Liu H, New AL, Pickles S, Porter A, Popova E, Allen JI, Siddorn J, Wood R (2017) Prospects for improving the representation of coastal and shelf seas in global ocean models. Geosci Model Dev 10:499-523. https://doi.org/10.1029/2006JC004034

Hua BL, Haidvogel DB (1986) Numerical simulations of the vertical structure of quasi-geostrophic turbulence. J Atmos Sci 43:29232936

Huthnance JM (1973) Tidal current asymmetries over the Norfolk sandbanks. Estuar Coast Mar Sci 1:89-99

Huthnance JM (1995) Circulation, exchange and water masses at the ocean margin: the role of physical processes at the shelf edge. Prog Oceanogr 35(4):353-431

Huthnance JM, Holt JT, Wakelin SL (2009) Deep ocean exchange with west-European shelf seas. Ocean Sci 5(4):621-634. https://doi.org/ 10.5194/os-5-621-2009

Irazoqui Apecechea M, Verlaan M, Zijl F, Le Coz C, Kernkamp H (2017) Effects of self-attraction and loading at a regional scale: a test case for the Northwest European Shelf. Ocean Dyn 67:729-749. https:// doi.org/10.1007/s10236-017-1053-4

Jacob B, Stanev EV (2017) Interactions between wind and tidally induced currents in coastal and shelf basins. Ocean Dyn 67:1263-1281. https://doi.org/10.1007/s10236-017-1093-9

Lelong M-P, Kunze E (2013) Can barotropic tide-eddy interactions excite internal waves? J Fluid Mech 721:1-27

Le Traon PY, Dibarboure G, Jacobs G, Martin G, Remy E, Schiller A (2017) Use of satellite altimetry for operational oceanography. In: Stammer D, Cazenave A (eds) Satellite altimetry over oceans and land surfaces. CRC Press, pp 581-608

Le Traon PY, Klein P, Hua BL, Dibarboure G (2008) Do altimeter wavenumber spectra agree with the interior or surface quasigeostrophic theory? J Phys Oceanogr 38:1137-1142. https://doi.org/10.1175/ 2007JPO3806.1

Le Traon PY, Rouquet MC, Boissier C (1990) Spatial scales of mesoscale variability in the North Atlantic as deduced from Geosat data, J Geophys Res 95:20267-20285

Luneva MV, Aksenov Y, Harle JD, Holt JT (2015; 31p) The effect of tides on the water mass mixing and sea ice in the Arctic Ocean.J Geophys Res 120. https://doi.org/10.1002/2014JC010310

Madec G (2008) NEMO ocean engine. Note du Pôle de modélisation. Institute Pierre-Simon Laplace (IPSL), France (27)

Maraldi C et al (2013) NEMO on the shelf: assessment of the IberiaBiscay-Ireland configuration. Ocean Sci 9:745-771

Mantovanelli A, Keating S, Wyatt LR, Roughan M, Schaeffer A (2017) Lagrangian and Eulerian characterization of two counter-rotating submesoscale eddies in a western boundary current. J Geophys Res Oceans 122. https://doi.org/10.1002/2016JC011968

McGillicuddy DJ Jr (2016) Mechanisms of physical-biologicalbiogeochemical Interaction at the oceanic mesoscale. Annu Rev Mar Sci 8:13.1-13.36. https://doi.org/10.1146/annurev-marine010814-015606

Morozov EG (1995) Semidiurnal internal wave global field. Deep-Sea Res 42:135-148

O'Dea EJ, Arnold AK, Edwards KP, Furner R, Hyder P, Martin MJ et al (2012) An operational ocean forecast system incorporating NEMO and SST data assimilation for the tidally driven European North- 
West shelf. J Oper Oceanogr 5(1):3-17. https://doi.org/10.1080/ 1755876X.2012.11020128

Munk W, Wunsch C (1998) Abyssal recipes II: energetics of tidal and wind mixing. Deep-Sea Res I Oceanogr Res Pap 45(12):1977-2010

Pichon A, Morel Y, Baraille R, Quaresma LS (2013) Internal tide interactions in the Bay of Biscay: observations and modelling. J Mar Syst 109-110(Supplement):S26-S44

Pingree RD, Le Cann B (1992) Three anticyclonic Slope Water Oceanic eDDIES (SWODDIES) in the southern Bay of Biscay in 1990. Deep-Sea Res 39(7/8):1147-1175

Polton JA (2015) Tidally induced mean flow over bathymetric features: a contemporary challenge for high-resolution wide-area models. Geophys Astrophys Fluid Dyn 109(3):207-215. https://doi.org/10. 1080/03091929.2014.952726

Ponte AL, Klein P (2015) Incoherent signature of internal tides on sea level in idealized numerical simulations. Geophys Res Lett 42: 1520-1526. https://doi.org/10.1002/2014GL062583

Qiu B, Nakano T, Chen S, Klein P (2017) Submesoscale transition from geostrophic flows to internal waves in the northwestern Pacific upper ocean. Nat Commun 7:14055-14010. https://doi.org/10.1038/ ncomms 14055

Ray RD, Mitchum GT (1997) Surface manifestation of internal tides in the deep ocean: observations from altimetry and island gauges. Prog Oceanogr 40:135-162

Ray RD, Zaron ED (2016) M2 internal tides and their observed wavenumber spectra from satellite altimetry. J Phys Oceanogr 46:3-22. https://doi.org/10.1175/JPO-D-15-0065.1

Richman JG, Arbic BK, Shriver JF, Metzger EJ, Wallcraft AJ (2012) Inferring dynamics from the wavenumber spectra of an eddying global ocean model with embedded tides. J Geophys Res 117: C12012. https://doi.org/10.1029/2012JC008364

Rocha CB, Chereskin TK, Gille ST, Menemenlis D (2016) Mesoscale to submesoscale wavenumber spectra in Drake Passage. J Phys Oceanogr 46:601-620

Savage AC et al (2017) Frequency content of sea surface height variability from internal gravity waves to mesoscale eddies. J Geophys Res Oceans 122:2519-2538. https://doi.org/10.1002/2016JC012331

Shakespeare C, Hogg A (2019) On the momentum flux of internal tides. J Phys Oceanogr 49(4):993-1013

Schloen J, Stanev EV, Grashorn S (2017) Wave-current interactions in the southern North Sea: the impact on salinity. Ocean Model 111:19-37

Souza AJ, Simpson JH (1996) The modification of tidal ellipses by stratification in the Rhine ROFI. Cont Shelf Res 16:997-1007

Stanev EV, He Y, Staneva J, Yakushev E (2014) Mixing in the Black Sea detected from the temporal and spatial variability of oxygen and sulfide - Argo float observations and numerical modelling. Biogeosciences 11:5707-5732. https://doi.org/10.5194/bg-115707-2014

Suanda SH, Feddersen F, Kumar N (2017) The effect of barotropic and baroclinic tides on coastal stratification and mixing. J Geophys Res Oceans 122:10,156-10,173. https://doi.org/10.1002/2017JC013379

Tchilibou M, Gourdeau L, Morrow R, Serazin G, Djath B, Lyard F (2018) Spectral signatures of the tropical Pacific dynamics from model and altimetry: a focus on the meso-/submesoscale range. Ocean Sci 14: 1283-1301. https://doi.org/10.5194/os-14-1283-2018

Tonani M, Sykes P, King RR, McConnell N, Péquignet A-C, O'Dea E, Graham JA, Polton J, Siddorn J (2019) The impact of a new highresolution ocean model on the Met Office North-West European Shelf forecasting system. Ocean Sci 15:1133-1158. https://doi.org/ 10.5194/os-15-1133-2019

van Sebille E, Griffies SM, Abernathey R, Adams TP, Berloff P, Biastoch A, Blanke B, Chassignet EP, Cheng Y, Cotter CJ, Deleersnijder E, Döös K, Drake HF, Drijfhout S, Gary SF, Heemink AW, Kjellsson J, Koszalka IM, Lange M, Lique M, MacGilchrist GA, Marsh R, Mayorga Adame CG, McAdam R, Nencioli F, Paris CB, Piggott MD, Polton JA, Rühs S, Shah SHAM, Thomas MD, Wang J, Wolfram PJ, Zanna L, Zika JD (2018) Lagrangian ocean analysis: fundamentals and practices. Ocean Model 121:49-75. https://doi. org/10.1016/j.ocemod.2017.11.008

Vervatis VD, De Mey-Frémaux P, Ayoub N, Sofianos S, Testut C-E, Kailas M, Karagiorgos J, Ghantous M (2019) Physicalbiogeochemical regional ocean model uncertainties stemming from stochastic parameterizations and potential impact on data assimilation. Geosci Model Dev Discuss. https://doi.org/10.5194/gmd2019-31

Vlasenko V, Stashchuk N, Hutter K (2005) Baroclinic tides: theoretical modeling and observational evidence. Cambridge University Press 351 pages, ISBN 0521843952

Wang Q, Danilov S, Hellmer H, Sidorenko D, Schröter J, Jung T (2013) Enhanced cross-shelf exchange by tides in the western Ross Sea. Geophys Res Lett 40(21):5735-5739. https://doi.org/10.1002/ 2013GL058207

$\mathrm{Xu}$ Y, Fu L-L (2012) The effects of altimeter instrument noise on the estimation of the wavenumber spectrum of sea surface height. J Phys Oceanogr 42(2229-2233):2012. https://doi.org/10.1175/JPOD-12-0106.1

Zaron ED (2017) Mapping the nonstationary internal tide with satellite altimetry. J Geophys Res Oceans 122:539-554. https://doi.org/10. 1002/2016JC012487 